\title{
Analysis Of Visual Rhetoric for Official Website City Government
}

\author{
M. Syahril Iskandar \\ Departement of Visual Communication \\ Design \\ Universitas Komputer Indonesia \\ Bandung, Indonesia
}

\begin{abstract}
The aim of the research to analyse benefits of the official website of city government. In addition, the main focus of this study is to examine visual rhetoric on the official website of Bandung City Government in an effort to attract the public to visit the site and can represent Bandung as the Creative City of the World. Unlike the previous, Information can only be accessed by a certain circle only or better known as Asymmetric Information. Now, the Information Technology Age has made it easy for people to access the information they want. In fact, the world and the information that is inside it can be accessed through the gadget in hand. Bandung City Government responded to this development by creating an official government website. Through its website, the city government of Bandung provide information on Employee Data and Mayor, Government Work Program, Public Service, Financial transparency, Tax and Retribution, until Public Patch. A Website cannot only present a number of Data but how to persuade and attract people to access the data through visual created so as to form Lead Public Perception. Visual image is a phenomenon of visual communication that transmits messages (government) to the message receiver (the people).Visual sign in text and still images is a representation of an object that produces a different understanding in viewing the visual object in semiotics study.
\end{abstract}

Keywords-Visual Rhetoric, website, Government

\section{INTRODUCTION}

Technology and information era has changed everything including selling and marketing system, education, and government system. A few years ago, when public need an information about government policy they need to come directly to the government office. Now a day public is able to access the news from the official website to get the data which is run by the local government. Almost every governmental in Indonesia has running the information trough website one of it are the city government of Indonesia [1].

Bandung is known as a creative city. A city of pop culture such as pop art, leisure, music, creative education, and life style. This message has been declared and issued with a notice by the UNESCO on December 2015 that Bandung as one of the creative cities network

Embedding Bandung as one of creative city by world organization as UNESCO is a world class rewarded and have special value to attract foreign tourists to visit Bandung, to fulfill the need of foreign tourism Bandung needs to provide website media that is easy to access from all over the world. Not only accessible but also persuasively attractive for people to get a complete information by visualizing the whole website design about Bandung. The main issue is had the visual design of website representing Bandung as a creative city? That can pursue the audience to access the information and persuasively invite the audience to visit Bandung.

Persuasion in visual is known as visual rhetoric. Douglas Ehninger in Smith., et al (2005, h 141) said rhetoric is not only about verbal symbol or visual, it's a wider understanding about visual object. The audience's mind and behavior can be influenced by visual rhetoric through strategic symbols. Therefore, its became the main issue to study the visual rhetoric of city government website as a creative city network.

\section{METHOD}

Visual rhetoric has two meanings. First, it refers to the visual image itself which in Visual Communication Design terminology is an objective study. While the second meaning is perspective reference or rhetorical approach used through three aspects of visual imagery: nature, function and evaluation. So in this study will reveal the first meaning of visual rhetoric, namely dissecting visual imagery built on the website and provide an overview of how visual rhetoric is built on the Bandung city government website as a creative city of the world. The method used in this study is qualitative descriptive method.

\section{RESULTS AND DISCUSSION}

In the Rhetoric perspective, visual rhetoric has two meanings, namely: visual rhetoric as a communication artifact that is visual works that have been created or exist using visual symbols that aim to influence the target audience from both psychological and behavioral perspectives. And the second is the visual rhetorical perspective which is an analysis to be able to see the communicative dimensions of visual works by looking at the whole picture which in the context of this research is the whole picture on the Bandung city government website from the first page (home page) to other pages.

First is the elements presented such as images, the style of images used through the main and other pages on the 
website. On the whole picture the main page will appear motifs resembling light blue and dark blue batik combinations, seen in Figure 1.

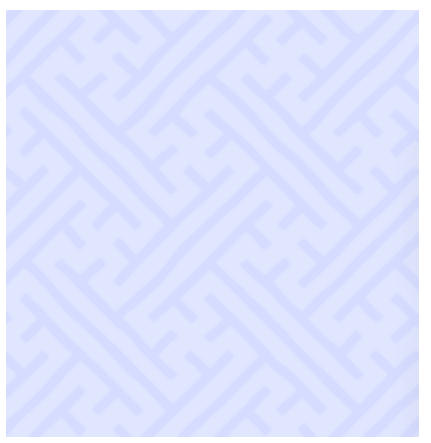

Fig 1. The main motive on the website display

From the view of design style, the picture represent bandung identity as a city of batik with geometric style and contemporary describe specific shape, as Teteh Cahyati from Batik Hasan said before. Antoher explanation coming from Netty Prasetyani about the different between Bandung's batik with other batik is because bandung has known as melting point or iconic city of other area in West Java.

On the left corner of website homepage there is a logo of Bandung with the acronym of Bandung City: .bdg followed by 'bandung.go.id' in blue. And under the caption written 'Portal Resmi Kota Bandung'. Meanwhile on the right top corner there is a searching menu represented by the symbol of loop or eye symbol, seen in Figure 2.

Fig 2. The top part of the website

The placement of the logo of the city of Bandung placed on the left side of the display in accordance with the direction of the eye, which is commonly used in Indonesian society and many countries move from left to right. This can be indicated as an effort by the government to inform the public of the identity and information on the position of the page that the audience is looking at. Through affirmation of the words as the official portal of the Bandung city government.

After the menu of various facilities available on the website, such as organizational structure (Pemerintah), facilities and infrastructure, at a glance, News about Bandung (Bandung Hari Ini) to the public service image shown next in the picture on the main page of the Bandung city government website featuring two figures the Bandung City leader used the flat design technique, namely Ridwan Kamil (as a Mayor) in the lower left corner of the screen and Oded M Danial (as a Deputy of Mayor) placed in the lower right corner of the screen, seen in Figure 3.

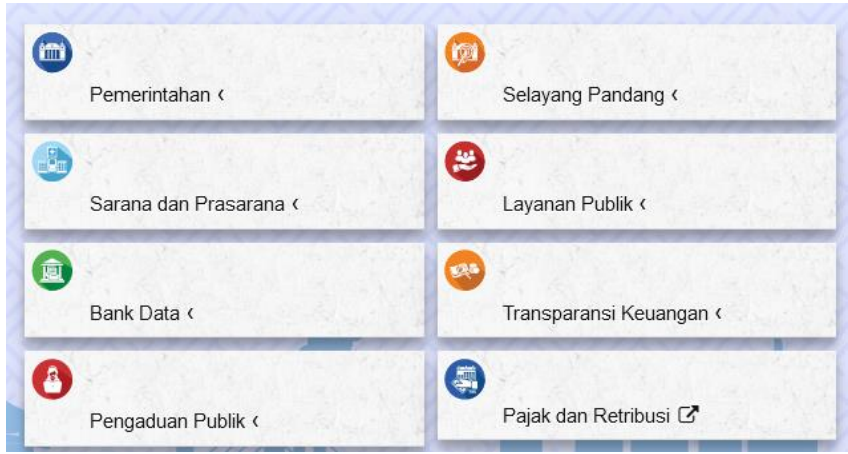

Fig 3. Display the main menu on the website

At the back of the picture the mayor and his deputy appear silhouette shown buildings resembling monuments of shoes and sandals shopping centers located in the Cibaduyut region, the Pasupati flyover, Monument of Bandung Lautan Api Tegal Lega area, Gedung Sate and several buildings in the city area Bandung, seen in Figure 4, and Figure 5.

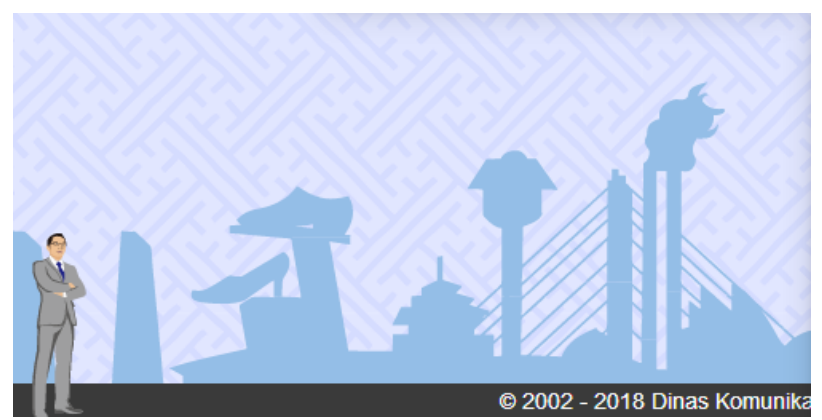

Fig 4. The lower left corner of the website

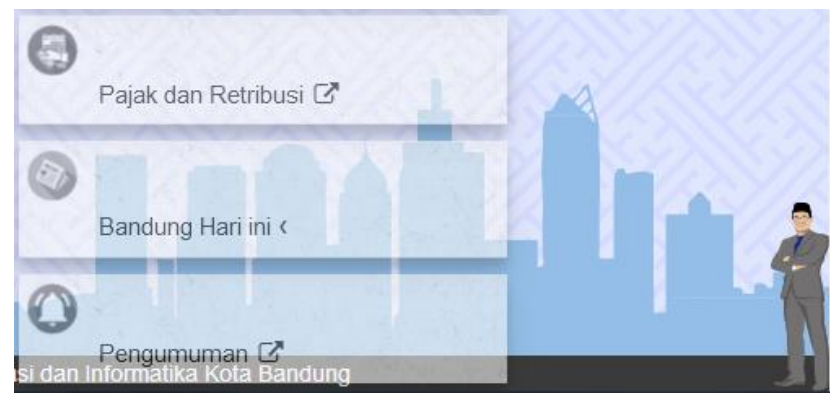

Fig 5. The lower right corner of the website

This can be seen as an effort of the city government of Bandung to show the public interesting places to visit, as well as an effort to portray Bandung as a city filled with tall buildings.

Based on the visual style of the Bandung city website, it can be identified as a flat drawing style or better known as flat design. In the 90 s there were many styles of drawing using gradients, drop shadows, and bevels that were once known as rich design. While the flat design is the opposite, the images are made as simple as possible and made solah together with the background. In other terms it can be said that flat design means eliminating shadow effects, gradients, textures, and other types that can make images into three dimensions. This picture style seems modern and allows the audience to be able to focus on the main message conveyed.

In the website, this image style can help speed up the image display process because of its small capacity in data storage. 
The first flat design style was introduced by The Swiss Style with the name Typographic, The Swiss Style which dominated in 1940 - 1950. Next Flat Design was found in the era of minimalism, where the design style in this era uses only the necessary elements, such as geometric shapes, related design ornaments, bright colors and clean lines. Like the work of The Blue Epoch Yves Klein. Which is now popular again through the design of world-leading companies such as Apple and Nike's design styles that are closely related to the company's image that is full of creativity and innovation.

Based on the description above can be captured the message to be constructed is Bandung as a creative city that is displayed through the style of images used on the official website of the city of Bandung.

Second, Suggested is big themes presented through the main and other pages on the website. Because one of the main factors of successful communication is when the message can be conveyed to the audience both through textual, verbal and visual. Like the ornament, lay out and color used on the Bandung city government website as a creative city.

At the end of the website, a full address is also displayed to be able to contact directly with the dominance of the black color as well as the cover on the website, seen in Figure 6.

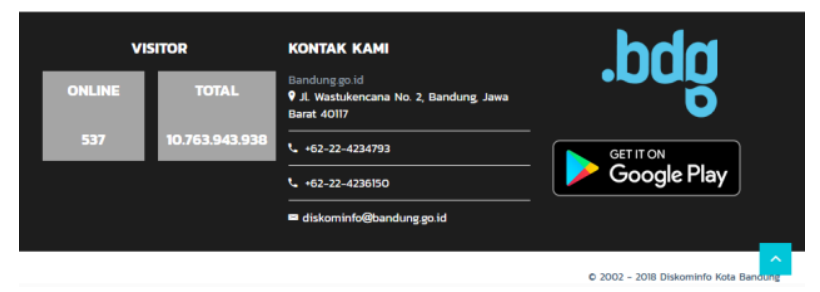

Fig 6. The final part of the website

\section{CONCLUSION}

The website is one of the media that can be accessed easily by users as the first source of information from various parts of the world. Website design that is able to represent people, institutions or companies and present messages can have effective persuasive power. So Visual Rhetoric is very necessary in constructing messages through visuals so that the audience is interested in visiting the city of Bandung and can perceive Bandung as a Creative city. This can be seen from the use of symbols and visual styles used.

\section{ACKNOWLEDGMENT}

The preferred spelling of the word "acknowledgment" in America is without an "e" after the "g". Avoid the stilted expression "one of us (R. B. G.) thanks ...". Instead, try "R. B. G. thanks...". Put sponsor acknowledgments in the unnumbered footnote on the first page.

\section{REFERENCES}

[1] G. Eason, B. Noble, and I. N. Sneddon, "On certain integrals of Lipschitz-Hankel type involving products of Bessel functions," Phil. Trans. Roy. Soc. London, vol. A247, pp. 529-551, April 1955. (references)

[2] J. Clerk Maxwell, A Treatise on Electricity and Magnetism, 3rd ed., vol. 2. Oxford: Clarendon, 1892, pp.68-73.

[3] I. S. Jacobs and C. P. Bean, "Fine particles, thin films and exchange anisotropy," in Magnetism, vol. III, G. T. Rado and H. Suhl, Eds. New York: Academic, 1963, pp. 271-350.

[4] K. Elissa, "Title of paper if known," unpublished.

[5] R. Nicole, "Title of paper with only first word capitalized," J. Name Stand. Abbrev., in press.

[6] Y. Yorozu, M. Hirano, K. Oka, and Y. Tagawa, "Electron spectroscopy studies on magneto-optical media and plastic substrate interface," IEEE Transl. J. Magn. Japan, vol. 2, pp. 740-741, August 1987 [Digests 9th Annual Conf. Magnetics Japan, p. 301, 1982].

[7] M. Young, The Technical Writer's Handbook. Mill Valley, CA: University Science, 1989. 